\title{
Integrated geophysical and mechanical study on the wooden structures of the ceiling of the Church of Beata Vergine Maria Assunta in Cielo
}

\author{
Lara De Giorgi ${ }^{1}$, Giovanni Leucci ${ }^{1}$, Davide Melica $^{1}$ \\ ${ }^{1}$ Institute for Archaeological and Monumental Heritage - National Research Council (IBAM-CNR) c/o Campus Universitario, Lecce, Italy
}

ABSTRACT

Non-destructive testing by mean of ground penetrating radar were performed on the wooden elements constituting the roofing of the Cathedral of Foggia. These measurements were related to the restoration work of the roof. Measurements campaign aimed at the assessment of the conservation status of the wooden elements of the all major and secondary elements of the truss of the nave, as well as on those main of the dome and the apse. Results show various abnormalities which correspond to nodes and/or slots. The presence of the nodes allow a rapid and accurate analvsis of the electromagnetic waves velocitv and the volumetric water content.

\section{Section: RESEARCH PAPER}

Keywords: wood elements; Geophysics; Measurements

Citation: Lara De Giorgi, Giovanni Leucci, Davide Melica, Integrated geophysical and mechanical study on the wooden structures of the ceiling of the Church of Beata Vergine Maria Assunta in Cielo, Acta IMEKO, vol. 7, no. 3, article 17, October 2018, identifier: IMEKO-ACTA-07 (2018)-03-17

Editor: Egidio De Benedetto, University of Salento, Italy

Received; June 27, 2018; In final form October 3, 2018; Published October 2018

Copyright: @ 2018 IMEKO. This is an open-access article distributed under the terms of the Creative Commons Attribution 3.0 License, which permits unrestricted use, distribution, and reproduction in any medium, provided the original author and source are credited

Corresponding author: Giovanni Leucci, g.leucci@ibam.cnr.it

\section{INTRODUCTION}

A discrete number of historic building structures in Italy are made of timber and the need of preservation is increasingly significant. Currently, several non-destructive testing (NDT) and minor-destructive techniques (MDT) are used in situ for assessing the physical and mechanical properties of wood structures $[1,2,3,4,5,6,7,8]$. These include ground penetrating radar (GPR) that is also used to inspect other materials such as masonry and concrete $[9,10,11]$.

In addition, there are specific NDT and MDT methods for wood, such as the micro-drilling resistance tool and xylotomic analysis [12]. Some of these techniques can be used for in situ evaluation of timber structures, including the GPR $[13,14]$ which yields results such as those presented at the Third International Conference on Metrology for Archaeology [33]. The Cathedral of Santa Maria de Fovea, which is directly linked with the patron saint "Madonna dei Sette Veli" (Madonna of the Seven Veils) in Foggia (Figure 1), was built in 1170 in Romanesque-Apulian style. Due to the earthquake that almost destroyed the Foggia town, it was strongly damaged. Later, in 1731 the Cathedral was re-built in Baroque style. The cathedral of Foggia is strictly connected to the discovery of the Icona-Vetere religious object, a table that depicts a rare portrait of the Virgin Kiriotissa with seven veils, (from which the name of the Madonna with Seven Veils).

In 2011, an intervention related to the restoration work of the roof required an in-situ investigation campaign aimed at the assessment of the conservation status of the wooden elements constituting the roofing of the Cathedral.

\section{NDT AND MDTS USED IN THIS WORK}

For this work the following methods were used: GPR (used device: IDS-Hi Mod with $2 \mathrm{GHz}$ antenna, Figure 2a), measurement of the drilling resistance (used device: Resistograph IML F400S, Figure 2b).

GPR is very important and powerful method for detecting nodes, internal cavities and microfractures. GPR method uses electromagnetic waves to investigate the internal structures of natural or human-made objects. Its wave frequency ranges from 10 to $2000 \mathrm{MHz}$. The GPR system consists of a data acquisition unit and of two (transmitter and receiver) antennas. The transmitter sends an electromagnetic wave pulse which is reflected to the receiver by an anomaly, if there is a difference in the complex permittivity between the anomaly and the surrounding environment. The maximum depth of wave propagation depends on the wave frequency and on the complex 


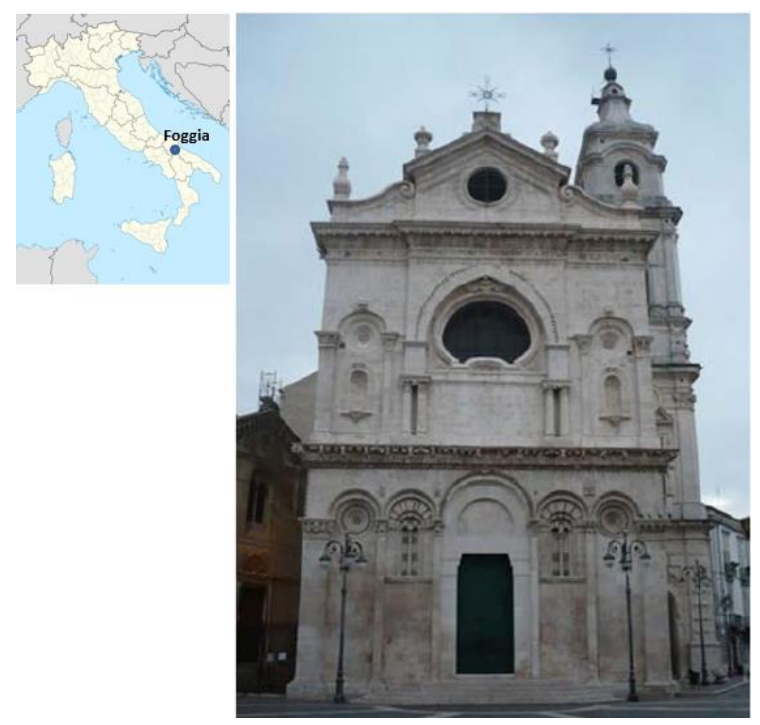

Figure 1. The Cathedral of Foggia.

permittivity of the investigated medium. The higher the frequency, the smaller the depth and the better the spatial resolution of the signal. The lower the wave frequency, the higher the depth and the smaller the spatial resolution. For example, a $2000 \mathrm{MHz}$ antenna (used in this study) can reach about $1 \mathrm{~m}$ with a resolution of about $1 \mathrm{~cm}$. The output of the GPR survey is a radar section of the investigated medium, where a point-shaped anomaly is outlined by a hyperbolic trace. The $\mathrm{X}$ axis corresponds to the direction of scanning, the $\mathrm{Y}$ axis is the depth. The data coming from the reflected echoes, saved in the data acquisition unit, are processed by filtering algorithms. The interpretation of the radar section permits the recognition of radar anomalies and their spatial location. These anomalies may reflect actual discontinuities, objects or voids.

Resistograph is an attachment to a Bosch drill that aids in the detection of decayed timber structures. It is based on a drilling resistance measuring method. A drilling needle with a diameter of $3 \mathrm{~mm}$ penetrates into a wooden element at a constant speed, and the drilling resistance is measured.

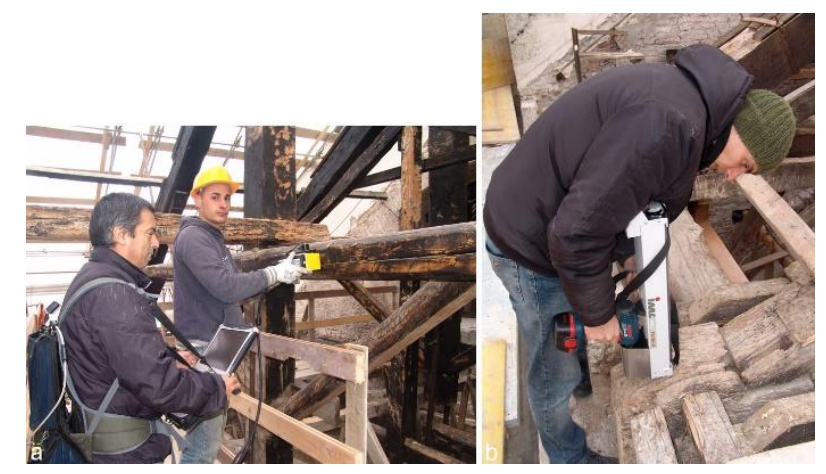

Figure 2 a) the GPR instrument (left); b) the Resistograph (right).

Resistograph gives drilling resistance along the drilling depth in the form of a dendrogram from which the Resistographic Measure (RM) parameter can be calculated. RM can be used for the estimation of modulus of elasticity (MoE), density, compressive strength or bending strength but the correlations are prevailingly moderate. The local character of Resistograph leads to preferable use of this technique for assessment of timber element interior state, internal voids, decay or loss in cross- section dimensions, which often cannot be seen from the outside. Resistograph is influenced by moisture content and possible deviation in drilling path.

Data are recorded on a wax paper strip at a 1:1scale and converted by an electronic unit. Graph-profiles can then be downloaded and analyzed. Because the drilling needle diameter is so small, the damage to the timber is quite insignificant.

\section{GPR DATA ACQUISITION AND ANALYSIS}

All GPR profiles were performed on wooden structures (Figure 3) and acquired at 1024 samples / track, the other acquisition parameters were optimized on site and held constant for each profile.

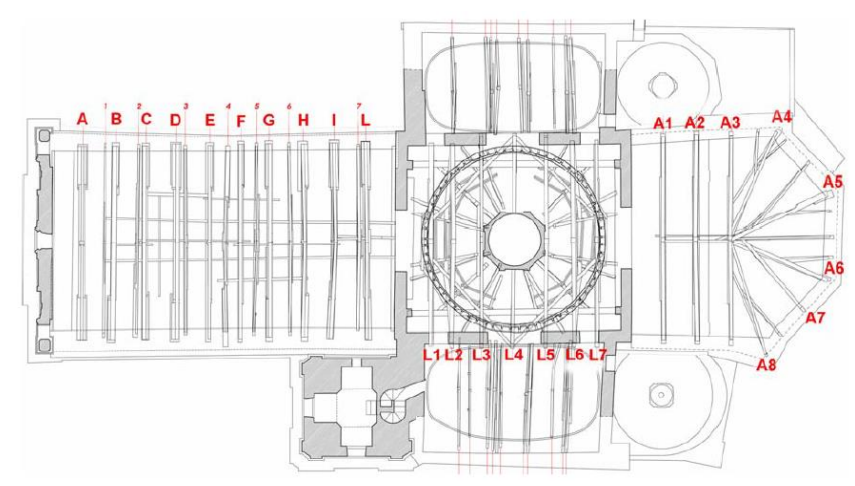

Figure 3. The roof planimetry: the red letters refer to the position of the wooden structures.

To eliminate the noise component present in the data and facilitate the interpretation, processing was realized through the following phases: i) background removal; ii) migration.

The presence of various anomalies due to small inhomogeneities, such as nodes and fractures, can be detected through a rapid and accurate analysis of the velocity of propagation of electromagnetic waves which allows also to obtain also the depth of the anomalies.

The analysis of the GPR data (Figure 4) shows that:

- the radar signal has an excellent penetration and crosses the element investigated for all its thickness;

- the surface portion of the wooden structures, for a thickness varying from 2 to $5-6 \mathrm{~cm}$, is generally characterized by reflections of weak amplitude, and this testifies to a net decrease in the density of the wood, probably related to both the activity of wood-eating insects and chemical attack; this anomaly appears to be more extensive on the extrados of the chains where the infiltration of rainwater, in the presence of large accumulations of guano, may have generated a corrosive action resulting in breakdown of the cellular elements of the wood;

- the numerous reflections in the shape of hyperbole, placed at various depths, indicate hardening of woody tissue that, in size and shape, can be related to nodes, single or in groups; their number, sometimes high, determines an average density including between 1.4 and 5.9 nodes per meter, but in some elements of the apse area will reach higher values;

- reflections with continuous development are generated by sub-horizontal fissures almost always oriented in the 

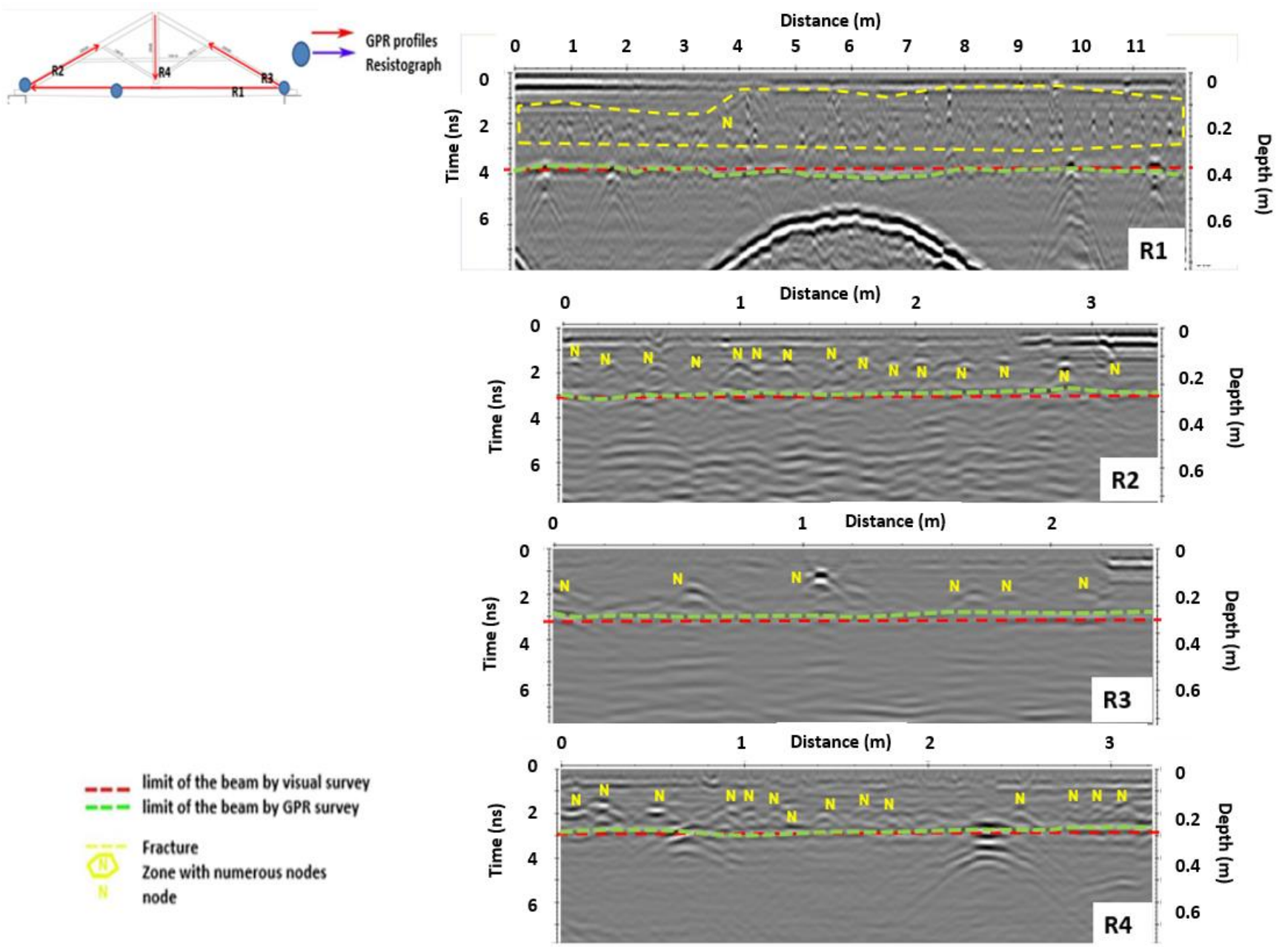

Figure 4. The processed radar sections.

direction of the grain; their width is generally close to $1 \mathrm{~cm}$;

- $\quad$ in some of the trusses wood elements B, C, F, G, L of the nave, the presence of cavities with dimensions of the order of $5 \mathrm{~cm}$ was recorded, probably due to biological attack. Similar anomalies, presumably correlated to fracture larger than those usually identified, were detected in the trusses L1 (chain, strut right monaco), L3 (chain), L5 (chain) and L6 (chain), the longitudinal development of these inhomogeneities varies from 15 to $35 \mathrm{~cm}$.

\section{VOLUMETRIC WATER CONTENT ANALYSIS}

Numerous studies have made use of GPR techniques to determine material moisture $[10,15,16,17,18,19]$.

However, since each technique is generally considered individually and is efficient only in a specific context, it is difficult to compare the results because of different field conditions. For the GPR frequency band, the velocity $v$ of EM-waves propagating in the ground depends on the relative dielectric permittivity (i.e. the real part of the dielectric constant, $K$ ) of the material; it is given by the simplified equation [20],

$v=c / K^{1 / 2}$

where $c$ is the EM-wave velocity in a vacuum $(0.30 \mathrm{~m} / \mathrm{ns})$.
Hence, $K$ can be determined directly from the EM-wave velocity similarly to what is done for time-domain reflectometry measurements $[27,28,29]$. For pure water, $K$ is about 80 , while for most dry geological material it varies between 4 and 10 . If only a small amount of water is contained in the material, the value of $K$ will increase considerably and, conversely, the EMwave velocity will decrease significantly. Thus, $K$ is a good measure of the water-content in the various materials, such as ground. Several formulae have been developed, both theoretically and empirically, to give the dielectric response of heterogeneous mixtures such as water-saturated soils. One such formula is the complex refractive index method (CRIM) equation, which is often used in the interpretation of EM logging data [21]. The major problem with the CRIM formula is that it does not take into account the geometrical information about the internal structure of rocks and about the microscopic fluid distribution. This has a significant effect on the dielectric properties of partially saturated rocks [22]. The above restriction may be overcome by using the Hanai-Bruggeman formula [22]. The main problem with the two previous approaches is that it is not possible to derive both the porosity and the water-content from the dielectric constant. Therefore, it is not possible to obtain information about the water-content without strong a priori assumptions. For this reason, it is preferable to use the well-known empirical equation, derived by Topp et al. [23], relating the dielectric response $K$ of various soil samples (with 


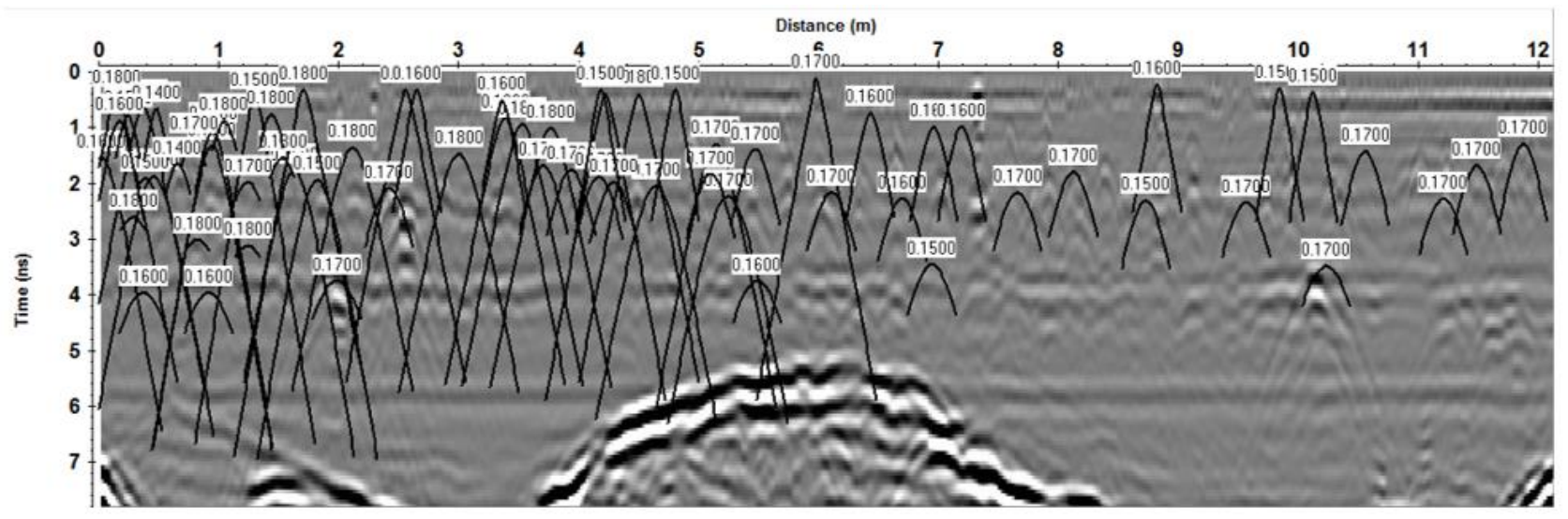

Figure 5. EM wave velocity estimation.

different degrees of saturation) to their net water-content $w$. This formula is given by

$$
w=-5.3 \cdot 10^{-2}+2.92 \cdot 10^{-2} K-5.5 \cdot 10^{-4} K^{2}+4.3 \cdot 10^{-6} K^{3}
$$

The EM-wave velocity can be estimated from GPR data in several ways [24, 25]; the conventional methods involve common depth-point (CDP) and wide-angle reflection and refraction (WARR) data sets. Both methods require two antennae in separate units and relatively long acquisition times. In the first case, both antennae are simultaneously moved apart on either side of the midpoint of the profile. In the second case, the position of one antenna is fixed while the other is moved along the profile direction. The EM-wave velocity can be more quickly and easily determined from the reflection profiles acquired in continuous mode, using the characteristic hyperbolic shape of reflection from a point source [26]. This is a very common method of velocity estimation and it is based on the phenomenon that a small object reflects EM-waves in almost every direction. In the data set, several hyperbolic reflections caused by objects of small dimensions such as node (Figure 4) are present, enabling EM wave velocity analysis to be performed $[30,31,32]$.
Figure 5 shows an example of velocity analysis performed on the data set. This represent the interactive velocity adaptation of a diffraction or reflection hyperbola using a hyperbola of defined velocity and width. The velocities are combined into a $2 \mathrm{D}$ model using a special interpolation method. The interpolation is performed as follows: all actual velocities are summed for every point in the $x-t$ range, proportional to the square of their distance from the $(x, t)$ point. This method provides only the average EM-wave velocity down to the depth of the source-point reflector. The EM-wave velocity was determined from the pointsource reflections. This method gives rms EM-wave velocities to the depth of the point-source reflector. Since in all radar sections acquired on the wooden structures, any interfaces with changes in EM-wave velocities between the surface and the target depth level are recorded, and the errors involved, compared to those obtained using interval velocities, are about $0.35 \%$. This early application, which uses a point-source reflection from a buried object to determine the average velocity, gives an accurate (qualitative) estimate of the subsoil volumetric water-content.

Successively, the volumetric water-content was determined from the dielectric properties of subsurface material, using the above empirical relationship (2). By applying the empirical Topp
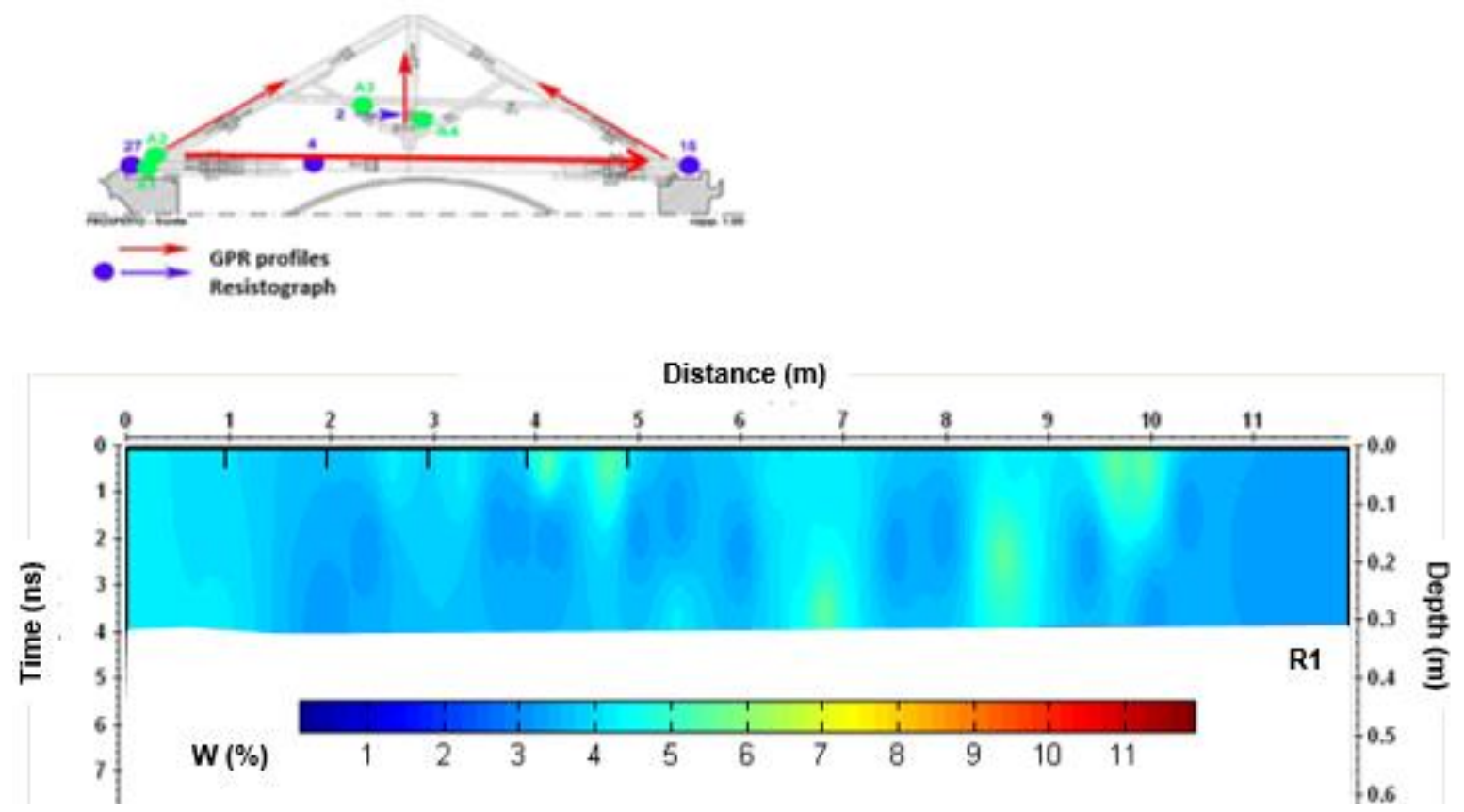

Figure 6. Volumetric water content analysis. 

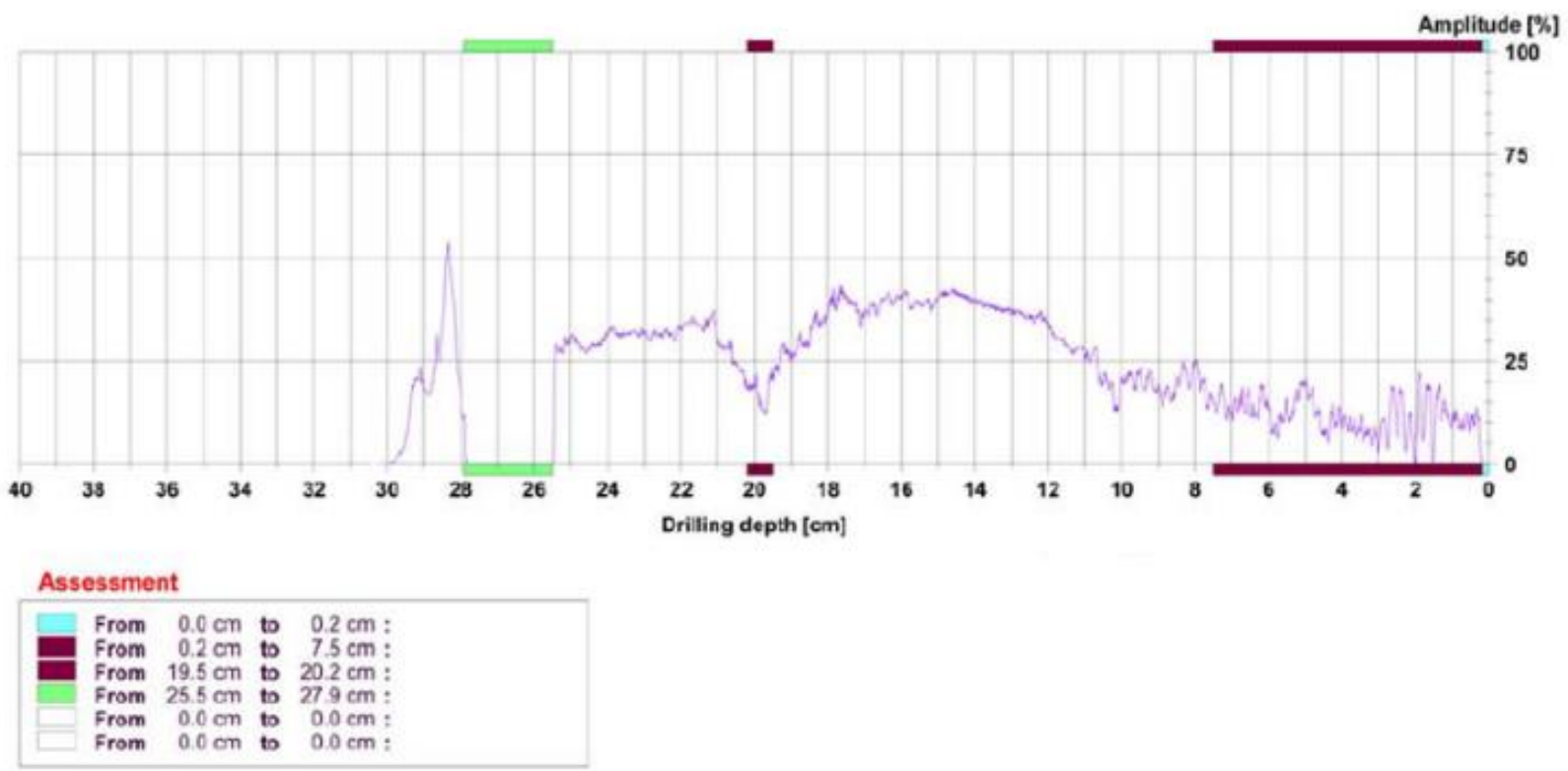

Figure 7. Resistographic curve.

formula (2), we then obtain an estimate of the average volumetric water-content of the wood; this varies from about 3\% to $6 \%$ (Figure 6). Water content was measured also through a direct mode using a wooden core and results agree with those obtained using the Topp formula.

\section{RESISTOGRAPHIC TESTS}

Resistographic tests carried out on wooden structures of the ceiling showed, for most of the investigated elements, a mediumlow drilling resistance, attributable both to the intrinsic characteristics of the Silver Fir wood (softwood) and to external factors responsible for an incipient or advanced decay.

An example of the results obtained by these tests is given by the curve in Figure 7, in which each of the suspect points, with low resistance, are easily distinguishable.

\section{CONCLUSIONS}

The integration of the GPR and resistographic tests data allowed to detect the presence of various abnormalities which correspond to nodes and/or slots, making possible a rapid and accurate analysis of the electromagnetic waves velocity of propagation and thus to obtain the depth of these anomalies. Among the main obtained data, it is worth stressing the following:

- the surface portion of the beams, for a thickness varying from 2 to $5-6 \mathrm{~cm}$, is characterized by abnormalities related to the activity of wood-eating insects and to chemical attack due to pigeon droppings;

- the numerous reflections in form of hyperbole, located at various depths, indicate that hardening of woody tissue can be mapped, both in size and shape, as nodes;

- the continuous reflections with a sub-horizontal development are generated by fissures almost always oriented in the direction of wood fibers;

- in some of the trusses wooden elements of the nave was recorded the presence of cavities with dimensions of about $5 \mathrm{~cm}$.
Volumetric water content analysis shows an approximately homogeneous distribution of the moisture in the analyzed woods elements.

The resistographic tests showed a medium-low resistance to penetration for most of the wooden elements investigated, that can be attributed both to the intrinsic characteristics of the wood employed and to external factors, such as the insects attack and guano deposition, responsible for their advanced deterioration.

\section{REFERENCES}

[1] C. M. Browne, W. E. Kuchar, 1985, Determination of material properties for structural evaluation of TRESTLE, in Proc. $5^{\text {th }}$ international nondestructive testing of wood symposium; 1985 September 9-11; Pullman, WA. Pullman, Wa: Washington State University, 361-384.

[2] J. Bodig, 2000, The Process of NDE Research for Wood and Wood Composites, in $12^{\text {th }}$ International Symposium on Nondestructive Testing of Wood.

[3] R. F. Pellerin, R. J. Ross, 2002, Nondestructive evaluation of wood, Eds. Pellerin,

[4] R. F. Ross, R. J. Forest Products Society, Madison, pp. ix-xi.

[5] V. Bucur, 2003, Non-destructive Characterisation and Imaging of Wood, Springer, Berlin.

[6] D. Ranalli, M. Scozzafava, M. Tallini, 2004, Ground penetrating radar investigations for the restoration of historic buildings: the case study of the Collemaggio Basilica (L'Aquila, Italy), «Journal of Cultural Heritage», 5, 91-99.

[7] M. Tiitta, 2006, Non-destructive methods for characterisation of wood material, $\mathrm{PhD}$ Thesis Univ. Kuopio.

[8] A. Sales, M. Candian, V. Cardin, 2011, Evaluation of the mechanical properties of Brazilian lumber (Goupia glabra) by nondestructive techniques, Construction and Building Materials, $25,1450-1454$.

[9] G. Leucci, N. Masini, R. Persico, F. Soldovieri, 2011, GPR and Sonic Tomography for Structural Restoration: the Case of the Cathedral of Tricarico, Journal of Geophysics and Engineering, 8, 76-92.

[10] G. Leucci, 2012, The use of GPR to estimate volumetric water content and reinforced bar diameter in Concrete Structures, Journal of Advanced Concrete Technology, 10, 411-422.

[11] F. Gabellone, G. Leucci, N. Masini, R. Persico, G. Quarta, F. Grasso, Nondestructive Prospecting and virtual reproduction of 
the chapel of the Holy Spirit in Lecce, Italy, Near Surface Geophysics, vol. 11, n. 2, pp. 231-238.

[12] A. C. Wiedenhoeft, 2012, Structure and Function of Wood. Handbook of Wood Chemistry and Wood Composites, second edition, pp.9-32; 2013. Chapter 2.

[13] I. Rodríguez-Abad, R. Martínez-Sala, R. Capuz-Lladró, F. García, R. Díez, 2008, Estudio de la variación del contenido de humedad en vigas de pino gallego por medio de la técnica no destructiva del georradar, II Jornadas de Investigación en Construcción, Madrid, Spain.

[14] I. Rodríguez-Abad, R. Martínez-Sala, R. Capuz-Lladró, F. García, L. Cabrelles, 2009, Application of the Non-Destructive GroundPenetrating Radar (GPR) Technique to the Restoration Works of a Timber Structure, I Congreso Internacional de Investigación en Edifi cación, Madrid, Spain.

[15] A. P. Annan, J. E. Scaife, P. Giamou, 1990, Mapping buried barrels with magnetics and ground penetrating radar. $60^{\text {th }}$ SEG Meeting, San Francisco, USA, Expanded Abstracts, 422-423.

[16] S. Du, P. Rummel, 1994, Reconnaissance studies of moisture in the subsurface with GPR. Proc. of the $5^{\text {th }}$ International Conference on Ground Penetrating Radar, pp. 1224-1248.

[17] J. S. Mellet, 1995, Ground penetrating radar applications in engineering, environmental management, and geology. Journal of Applied Geophysics 33, 157-166.

[18] G. Grandjean, J. C. Gourry, A. Bitri, 2000, Evaluation of GPR techniques for civil-engineering applications: study on a test site. Journal of Applied Geophysics 45, 141-156.

[19] G. Leucci, S. Negri, M. T. Carrozzo, L. Nuzzo, 2002, Use of ground penetrating radar to map subsurface moisture variations in an urban area. Journal of Environmental and Engineering Geophysics 7(2), 69-77.

[20] J. L. Davis, A. P. Annan, 1989, GPR for high resolution map ping of soil and rock stratigraphy. Geophysical Prospecting 37, 531-551.

[21] R. J. Greaves, D. P. Lesmes, J. M. Lee, N. Toksöz, 1996, Velocity variations and water content estimated from multi-offset, ground-penetrating radar. Geophysics 61, 683-695.

[22] A. L. Endrea, R. Knight, 1992, A theoretical treatment of the effect of microscopic fluid distribution on the dielectric properties of partially saturated rocks. Geophysical Prospecting $40,307-324$.

[23] G. C. Topp, J. L. Davis, A. P. Annan, 1980, Electromagnetic determination of soil water content: measurements in coaxial transmission lines. Water Resources Research 16(3), 574-582.

[24] L. B. Conyers, D. Goodman, 1997, Ground-penetrating Radar An Introduction for Archaeologists. Alta Mira Press, Walnut Creek.
[25] J. A. Huisman, S. S. Hubbard, J. D. Redman, A. P. Annan, 2003, Measuring soil water content with ground penetrating radar: A review. Vadose Zone Journal 2, 476-491.

[26] R. K. Fruhwirth, R. Schmoller, E. R. Oberaigner, 1996, Some aspects of the estimation of electromagnetic wave velocities. Proc. of the $6^{\text {th }}$ International Conference on Ground Penetrating Radar, Tohoku University, Sendai, Japan, pp. 135-138.

[27] A. Cataldo, E. Piuzzi, E. De Benedetto, G. Cannazza, (2014), Experimental characterization and performance evaluation of flexible two-wire probes for TDR monitoring of liquid level. IEEE Transactions on Instrumentation and Measurement, 63(12), 2779-2788.

[28] A. Cataldo, E. De Benedetto, G. Cannazza, C. Huebner, D. Trebbels, (2017), Performance comparison of TDRbasedsystems for permanent and diffused detection of water content and leaks. Measurement Science and Technology, 28(1), $1-8$.

[29] A. Cataldo, E. De Benedetto, G. Cannazza, E. Piuzzi, E. Pittella, (2018), TDR-based measurements of water content in construction materials for in-the-field use and calibration, IEEE Transactions on Instrumentation and Measurement, 67(5), 12301237.

[30] A. Cataldo, E. De Benedetto, G. Cannazza, G. Leucci, L. De Giorgi, C. Demitri, (2017), Enhancement of leak detection in pipelines through time-domain reflectometry/ground penetrating radar measurements. IET Science, Measurement and Technology, 11 (6), 696-702.

[31] R. Persico, G. Leucci, L. Matera, L. De Giorgi, F. Soldovieri, A. Cataldo, G. Cannazza, E. De Benedetto, (2015), Effect of the height of the observation line on the the diffraction curve in GPR prospecting. Near Surface Geophysics, 13(3), 243-252.

[32] A. Cataldo, R. Persico, G. Leucci, E. De Benedetto, G. Cannazza, L. Matera, L. De Giorgi, (2014), Time domain reflectometry, ground penetrating radar and electrical resistivity tomography: A comparative analysis of alternative approaches for leak detection in underground pipes. NDT and $\mathrm{E}$ International, 62, 14-28.

[33] G. Quarta, G. Leucci, R. Persico, P. Durante, S. Giammaruco, 2017, Geophysical investigations on hypogeic monument. The case study of the Crypt of St. Sebastian in Sternatia (Lecce Southern Italy). Proc. of $3^{\text {td }}$ IMEKO International Conference on Metrology for Archaeology and Cultural Heritage, 350-352, ISBN: 978-92-990084-0-9. 